\title{
REMOVER PARA PROMOVER: ESPAÇO CONCEBIDO E REPRESENTAÇÕES DO ESPAÇO NO BAIRRO RESTINGA - PORTO ALEGRE/RS ${ }^{1}$
}

\author{
NOLA PATRÍCIA GAMALHO ${ }^{2}$ \\ Universidade Federal do Rio Grande do Sul
}

\section{Pensando o espaço e representações}

A proposta aqui apresentada é trazer para discussão a constituição do bairro Restinga, em Porto Alegre, RS. Para tanto, é indispensável que se relacione a sua produção material à produção de suas representações: o espaço de representação e, mais pontualmente neste artigo, as representações do espaço (LEFEBVRE, 2000). O conhecimento generalizado sobre a Restinga é superficial e distorcido, constituindo o espaço do medo e da precariedade, sendo esses valores transpostos aos moradores do bairro. Contudo, é importante identificar os elementos que originaram o espaço e as suas representações.

A constituição das distinções socioespaciais e seus estigmas estão presentes na produção da Restinga, materializando-se de maneira explícita ou velada na forma espacial, nas políticas públicas e nas representações. No bairro, é visível que as desigualdades se vestem de distinção e, nesse sentido, torna-se imprescindível desconfiar do senso comum, desconfiando da naturalização de uma sociedade hierarquizada.

Esse entendimento acerca da produção do espaço Restinga está embasado na tríade espaço concebido (da visão dos planejadores, teóricos e o conhecimento generalizado no senso comum), espaço vivido (corpóreo,

\footnotetext{
${ }^{1}$ Este artigo é um recorte da dissertação de mestrado intitulada A produção da periferia: das representações do espaço ao espaço de representação no Bairro Restinga - Porto Alegre/RS, disponível em meio digital no endereço http://www.lume.ufrgs.br/handle/10183/16658. A dissertação foi orientada pelo professor Doutor Álvaro Luiz Heidrich.

${ }^{2}$ Mestre em Geografia pela Universidade Federal do Rio Grande do Sul.
} 
afetivo, significativo na própria história de vida) e espaço percebido (das práticas socioespaciais) (LEFEVBRE, 2000). O espaço concebido está associado à produção das representações do espaço, e o vivido, ao espaço de representação. Uma rua tem um traçado, uma racionalidade, é concebida ao mesmo tempo que é vivida, nos trajetos, nas relações entre os sujeitos, nas suas funções. São planos que se imbricam, influenciando-se mutuamente. Contudo, a discussão aqui apresentada está centrada no espaço concebido e nas representações do espaço.

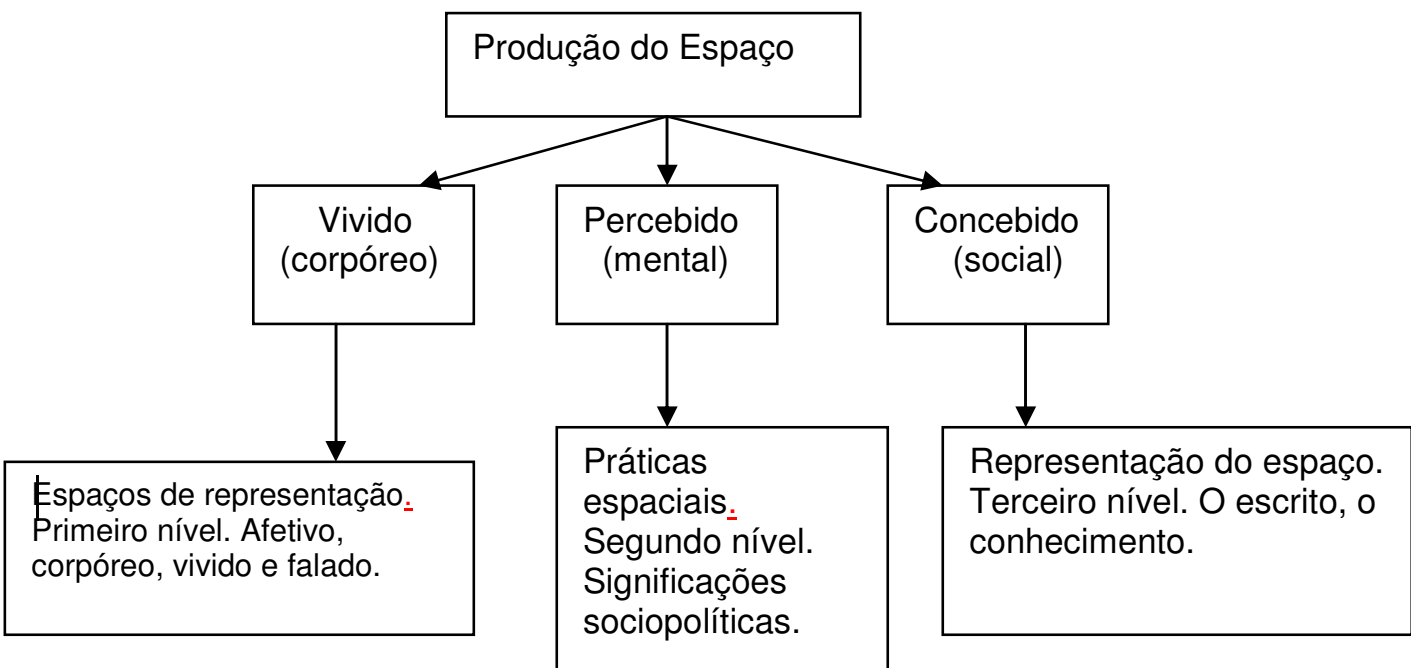

Figura 1. Tripé sobre a produção do espaço.

Fonte: CARDOSO, Cristiane.

Dessa forma, busca-se compreender a Restinga a partir de sua formação, a relação entre as remoções das "Vilas de Malocas" e a constituição de um bairro periférico, elaborando-se um entendimento da produção espacial e de suas representações.

O espaço é uma produção social ao longo do processo histórico (CARLOS, 2007), atravessado por intencionalidades ocultas ou reveladas conforme os objetivos de sua produção. Entende-se, portanto, o "(...) espaço como produto material, com a relação entre as estruturas sociais e espaciais do urbanismo e com o conteúdo ideológico do espaço socialmente criado" (SOJA, 1993, p. 97). É abstração que perpassa interesses associados a diferentes planos, articulando a ordem distante (do Estado, das instituições) e a ordem próxima (relações de vizinhança) (LEFEBVRE, 2006). Faz parte das estratégias do capital, das relações de poder e da experiência de vida dos sujeitos. 
Em sua produção, o espaço é fragmentado de forma que as intencionalidades presentes na ordem distante predominem. Ora, como produto da fragmentação, tem-se a valorização diferencial, agregando valores e status, elitizando e estigmatizando os espaços de forma distinta. O Estado, em conjunto com os empreendedores imobiliários, intensifica a característica do espaço urbano enquanto valor de troca. Tem-se a contradição entre a reprodução ampliada do capital, as necessidades econômicas e políticas, e a reprodução da vida. Carlos (2001, p. 15) destaca a ação do poder público a serviço do capital:

A ação do Estado - por intermédio do poder local — ao
intervir no processo de produção da cidade reforça a
hierarquia de lugares, criando novas centralidades e
expulsando para a periferia os antigos habitantes, criando um
espaço de dominação. Com isso, impõe sua presença em
todos os lugares, agora sob controle e vigilância (seja direta
ou indireta). Nesse nível de realidade o espaço produzido
assume a característica de fragmentado (em decorrência da
ação dos empreendedores imobiliários e da generalização do
processo de mercantilização do espaço), homogêneo (pela
dominação imposta pelo Estado) e hierarquizado (pela divisão
espacial do trabalho).

A metamorfose do solo em mercadoria compõe uma forma sutil de dominação, cujo produto — a segregação — é percebido como um efeito espontâneo da produção da cidade, encobrindo a contradição entre cidade formal e informal. São processos que na cotidianidade tornam-se alienados, ocultos nas produções ideológicas e amalgamados às representações do espaço.

Não são processos simples, pois para a sua legitimidade tem-se a necessidade de enquadramento simbólico das distinções sociais, que são materializadas nas possibilidades de consumo. É o duelo constante entre os atores hegemônicos e os hegemonizados (SANTOS, 2002). Percebe-se que há um campo de força na produção do espaço e que alguns segmentos impõem mais fortemente a sua lógica nessa produção.

A partir da perspectiva das distinções sociais, Bourdieu traz uma importante contribuição, ao definir o espaço social como uma forma de representar o mundo social, suas diferenciações e distribuições: "os agentes e grupos de agentes são assim definidos pelas suas posições relativas nesse espaço social" (2007, p. 134). É, em sua forma e conteúdo, um complexo mosaico de fragmentos, sendo que, segundo Santos (1987, p. 81), “cada 
homem vale pelo lugar onde está, o seu valor como produtor, consumidor, cidadão, dependente de sua localização no território". A diferenciação social a partir do capital cultural e do estilo de vida traduz a condição de classe do sujeito, localizando-o na estratificação do espaço. É a partir desse intrincado jogo entre planos distintos (econômico, político e social) e representações sociais que o diálogo acerca da produção do bairro Restinga é desenvolvido.

\section{As vilas de malocas: trilhando os caminhos da origem da Restinga}

Uma estratégia da dominação de classe é a produção de representações que naturalizam as alteridades, ocultando sua lógica. A cidade compõe um mosaico não apenas de texturas e morfologias, mas também de símbolos, significados e representações, compondo trunfos, armas na reprodução e legitimação do sistema de dominação. Partindo desse pressuposto, tem-se o imaginário das vilas de malocas e seus reassentamentos como fatos que originaram o espaço Restinga e as suas representações.

As remoções de populações pobres para áreas periféricas e seu alicerce na constituição de valores morais, paisagísticos e assépticos que legitimassem as remoções foram recorrentes na história de Porto Alegre. Exemplo disso foram as remoções realizadas no final do século XIX e início do século XX, quando os becos e cortiços que ocupavam o centro da cidade foram removidos para os então arrabaldes, lugares destinados aos pobres.

Nesse momento de fim de século, o beco foi identificado como o reduto das sociabilidades condenadas, era um espaço maldito da cidade, frequentado pelos "turbulentos" da urbe. A situação se definia tanto mais grave porque tais espaços estigmatizadores se achavam encravados no centro da cidade, que se encontrava em processo de renovação e saneamento, tanto técnico quanto moral. Verdadeiros "lugares de enclave", eles ameaçavam a ordem, pois expunham, pela contiguidade inevitável e indesejável, o mau lado da urbe. Para os cidadãos da Porto Alegre ordenada e disciplinada que viviam no centro, o "pecado" morava ao lado (PESAVENTO, 2001, p. 98).

Os cortiços e becos simbolizavam o não aceito na sociedade, constituíam a materialidade física e espacial das distinções, que eram 
ancoradas em representações que remontavam à promiscuidade, ao desleixo e à marginalidade (MOSCOVICI, 2003). Na década de 1940 houve novamente a demanda por remoções, dado o crescimento da cidade. Nesse momento, os anteriores arrabaldes tornaram-se alvo do "urbanismo" da cidade, levando a administração municipal a empreender novamente o processo de remoções. O símbolo dessa nova espacialidade era a moradia denominada maloca, que formava, consequentemente, as vilas de malocas. Medeiros, teórico contemporâneo desse processo, explicita os elementos da representação dessas vilas, identificando-as como desajustadas ao padrão asséptico e moral desejado na época.

Em 1946 e especialmente em princípios de 1947 começou-se a observar o aparecimento de grupos mais ou menos numerosos de casebres em vários pontos da cidade.

Sempre existiram centenas de casebres e mesmo grupos localizados em determinados lugares. Mas por esta época (4647) o fato apresentou características novas. A construção em massa em lugares determinados - terrenos baldios, margem de estrada, logradouros públicos - apresentou um ritmo acelerado, a ponto de aparecerem da noite para o dia verdadeiras vilas, que os próprios habitantes apelidaram de "vilas de malocas" (MEDEIROS, 1951, p. 15).

As vilas de malocas (Figura 2) não harmonizavam com o ideal de modernidade e progresso e ocupavam setores estratégicos para o desenvolvimento urbano, mas consistiam no modo pelo qual um segmento social produzia a própria existência e seu lugar. Paralelamente ao crescimento das vilas, a cidade passava por um processo de intensas transformações, e a esse crescimento populacional era atribuído o caráter de desorganizado, necessitando, portanto, de ordenamento. A pobreza tornava-se visível no modo de habitar, de ocupar a cidade, e a maloca era a materialização do processo. 


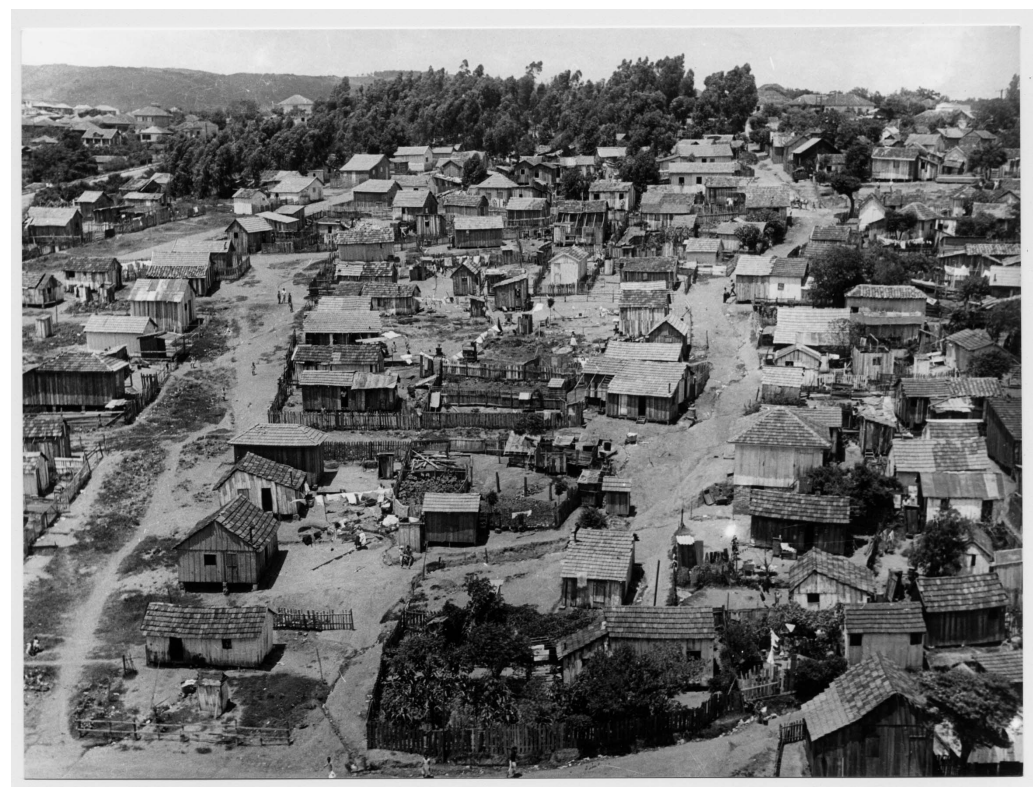

Figura 2. Vila Santa Luzia em 1956. Fonte: Léo Guerreiro de Pedro Flores - Acervo do Museu Joaquim Felizardo/Fototeca Sioma Breitman.

A distinção social não é apenas paisagística, não se reduz à forma, mas atravessa o direito de habitar, pautado por relações monetarizadas e normatizadas do acesso ao solo. As vilas de malocas constituíam a subversão a esse sistema: eram a estratégia de habitar a cidade, tornando-se o símbolo de um determinado modo de vida. Ora, é a constituição das representações, igualando imagens a ideias e ideias a imagens.

O imaginário das malocas incorporava a ideia de contaminação, atribuindo ao modo de vida dos "maloqueiros" uma questão patológica. A produção da alteridade a partir de valores morais é constante nas descrições das malocas, produzindo representações fortemente estigmatizadoras.

Em breves palavras, eis aqui a monografia dessa família. Reside numa casa tipo "inominável" (...) é uma "malóca" mal construída com alguns restos de madeira e os mais variados pedaços de latas enferrujadas; em forma de meia-água, com $2,10 \mathrm{~m}$ de altura na frente e $1,80 \mathrm{~m}$ nos fundos; tem $2,5 \mathrm{~m}$ por 2,50 m de lado, isto é, 6,25 $\mathrm{ms}^{2}$; ésta superfície ainda foi subdividida, pois fizeram como que um quarto, sem porta, 
comportando exiguamente uma cama, que é a única ali existente [sic]. (MEDEIROS, 1951, p. 32).

Embora um produto ideológico a serviço do reordenamento espacial, o texto aponta para as condições das habitações. A precariedade é manifesta, não sendo, contudo, identificada como um produto da sociedade, mas como algo intrínseco a essa população.

\begin{abstract}
Nessa "malóca", vivem sete pessoas: a mãe, cinco filhos e o amante de uma das filhas. Maior promiscuidade é impossível. T., que é a mãe, nasceu em Palmares, morou 20 anos em Osório, era casada, separou-se lá do marido para viver com outro, de quem teve os cinco filhos; veio há um ano para Porto Alegre, desde então está na "vila". Os filhos têm as idades de 17, 15, 10, 8, 7, 4 anos; homem é só o de 7 anos. A primeira filha amasiou-se aos 16 anos com V., de 28 anos, natural de Osório e aqui está há um ano; moram na aludida "malóca"; e a segunda aos quatorze anos passou a viver com um irmão de V., que aqui está também há um ano. Nesse ambiente vivem 4 crianças de 10 a 4 anos. Só o milagre impediria que estas criancinhas também não se pervertessem (...). E aquelas 125 crianças de 0 a 14 anos (...) vão adquirindo hábitos viciosos de toda sorte num meio vicinal e familiar, onde apenas esporadicamente se cogita a existência das virtudes, mesmo aquelas básicas, para o desenvolvimento pessoal e o bem estar social, e onde os exemplos e as condições materiais são as mais desfavoráveis à formação das novas gerações [sic]. (MEDEIROS, 1951, p. 32-33).
\end{abstract}

A produção das representações das malocas foi útil, pois desempenhou um papel ideológico na produção da distinção dos sujeitos a partir de sua localização no espaço social. O discurso determinista na construção das alteridades e a permanência da degradação que percorre as gerações, contaminando-as, são elementos da representação das malocas.

Prescindindo de todos os riscos para a saúde pública e inconvenientes para a beleza urbana, devemos considerar o que essas "vilas" significam para as novas gerações que nelas surgem: numerosos indivíduos que não participam razoavelmente do bem comum que a sociedade deve assegurar; indivíduos que se acham num estado invencível de miséria material, cultural e moral, sem que a sua condição seja encarada à luz de conhecimentos científicos e técnicos, das ciências sociais e das ciências práticas, com que os 
administradores modernos podem contar; novas gerações, em fase de propagação, que podem contaminar pela repercussão em cadeia toda a estrutura social e moral da nação. Si a vizinhança é fato sobremodo importante para a formação do individuo e da sociedade, quer pelo que importa ao aspecto positivo do desenvolvimento pessoal e social, quer pelo aspecto negativo da degradação e da contaminação, as "vilas de malócas" infelizmente são fatos que se apresentam sobre este último aspecto [sic]. (MEDEIROS, 1951, p. 66-67).

As representações presentes no texto constituem uma produção intelectual, reproduzida no senso comum e nos meios institucionais, corroborando a perspectiva de um planejamento urbano pautado na segregação. A questão era apresentada como um problema intrínseco à condição de morador da maloca e um obstáculo ao desenvolvimento urbano. Têm-se os pressupostos para a política de remoção das malocas, pois estas configuravam um atraso ao processo da modernização e uma patologia social. As representações desses espaços foram imprescindíveis para aplicação das políticas de remoções que se iniciariam no final da década de 1960.

\section{Da vila de malocas à periferia: a invenção do bairro Restinga}

O bairro Restinga surgiu na reconfiguração gerada pelas remoções das vilas de malocas (Figura 3). Foram os processos de transformação que destruíram e recriaram formas com novas funções, e a Restinga constituiu uma das novas espacialidades da cidade. Sua produção envolveu os planos do percebido, do concebido e do vivido, que ocorreram a partir de oposições e conflitos (entre os moradores das malocas e o poder público), sendo explícita “(...) a contradição entre as estratégias do Estado (visando à reprodução do capital e à produção de um espaço dominado) e os usos do espaço (objetivando a reprodução da vida) (...)" (CARLOS, 2001, p. 17). A produção de formas da urbanização ocorre no intuito de gerar as condições para a reprodução do capital. Nesse sentido, a cidade é consumida intencionalmente. A criação da Restinga, em 1967, em uma área da periferia distante cerca de $26 \mathrm{~km}$ do centro administrativo de Porto Alegre, fez parte desse processo envolvendo múltiplos planos e incidindo no lugar, alterando o espaço e as vidas. Havia a intencionalidade da ordem distante se projetando e alterando a morfologia urbana, mas esquecendo as vidas que ali estavam. 
Nesse processo, a manipulação das representações das vilas de malocas e seus moradores serviu para legitimar a remoção, identificando essa população como desajustada da Porto Alegre que se almejava. Como estratégia de legitimação, associou-se a noção de malocas a adjetivos que emetiam à condição de conflitos ou enclausuramento, como pode ser observado em jornais da época: "Célio vai confinar as malocas. Conforme determinação do prefeito tôdas as malocas existentes atualmente em zonas residenciais serão removidas e confinadas em uma gleba de terra adquirida pela Prefeitura na Estrada da Restinga... [sic]" (Zero Hora, 17 de nov. 1966, p. 2).

A consolidação das representações sociais das malocas e do progresso produziu um consenso acerca das remoções da população dessas vilas, que tiveram intenso crescimento em núcleos e em população durante as décadas de 1960 a 1970. Em 1973, Porto Alegre possuía 124 núcleos irregulares, com 20.152 malocas, 22.336 famílias e 105.833 habitantes (DEMHAB, 1973). A amplitude da questão atingia níveis que não podiam mais ser ignorados; contudo, permanecia a associação da questão social a patologias e, enquanto herança social, aspectos presentes no senso comum e no âmbito do planejamento, em materiais técnicos de autarquias municipais. "As malocas em Porto Alegre já ultrapassaram a fase migratória do fenômeno e encontram-se há algum tempo em outra mais avançada, em que o favelamento é autoperpetuável.” (DEMHAB 1973, p.34). 


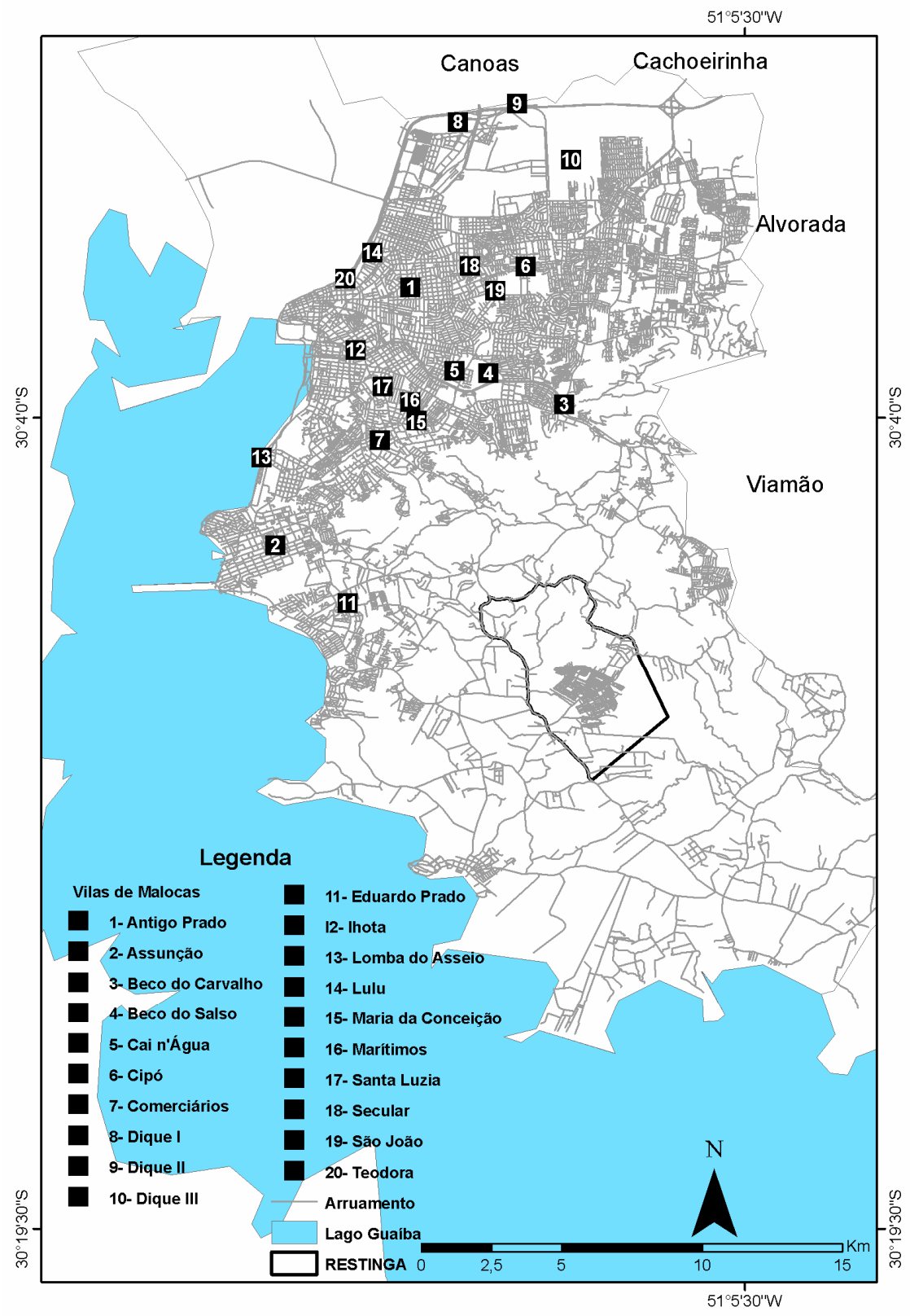

Figura 3. Localização das Vilas de Malocas em Porto Alegre. Fonte: Nola Gamalho, 2009. 
O desfavelamento consistiu em retirar núcleos habitacionais de baixa renda de alguns setores que, sob o pretexto da promoção e do saneamento urbanos, produziu novos contextos. Foi então agregado um novo solo à cidade, cuja finalidade era de abrigar a população das malocas. Os principais locais de recebimento dessa população foram a Restinga, que na época pertencia ao bairro Belém Novo, e a Mapa, que pertencia ao bairro Lomba do Pinheiro.

Um dia surgiu a avenida. Já existia, mas agora tornara-se a
AVENIDA... Iluminação a mercúrio. Uma beleza. Mas
iluminada demais, ressaltava a feiúra das malocas. Era preciso
removê-las e rapidamente. Os caminhões surgiram. Ninguém
sabia o que era a tal Restinga, para onde iriam todos
compulsoriamente... Um passarinho informara que seria uma
espécie de Vila Mapa... Um pouco aborrecidos, um pouco
esperançosos, lá se foram êles... Quilômetros e quilômetros de
estrada e ao final o deserto... [sic] (FAILLACE, Zero Hora,
18 maio. 1967, p. 12-13)

As malocas constituíam uma escrita na cidade, materializavam-se no traçado, na moradia, nos modos de vida, com personagens e histórias, sendo percebidas e classificadas de acordo com códigos estéticos, morais e científicos. As representações sociais das malocas e de seus moradores identificavam o modo de vida e as próprias estratégias de sobrevivência como desajustados à cidade formal, o que corroborava a legitimidade da eliminação das malocas e a proposta de ressocialização de seus habitantes. Esse imaginário era alicerçado em dados objetivos, sensíveis à percepção, como a própria maloca, e a dados subjetivos, como valores e moralidade.

De forma descontextualizada, as concepções vigentes enclausuravam os moradores das malocas na condição de inferioridade e a política pública de remoção e urbanização atuaria no intuito de retirar a condição de "maloqueiro" desses sujeitos. Associava-se a população e a problemática social a desvios que se materializavam na estratificação social, na forma de ocupação do solo, na inserção no mercado de trabalho (formal e informal) e na esfera cultural, a partir dos modos de vida.

A solução da problemática reduzia-se à reeducação e ao acesso ao lote, pois, segundo os ditames morais e sociais, essa população não estava apta a viver em sociedade. O imaginário social foi fortemente vinculado a essas prerrogativas, como pode ser observado nas notícias da época: "O prefeito informou que é pensamento da administração municipal seguir o 
plano de Vilas de Triagem, onde o elemento seria educado para cohabitar." (Zero Hora, 27 de fev. 1969, p. 2).

Associando-se às políticas de urbanização, tem-se a limpeza social de setores da cidade, processo que corresponde à racionalidade presente na lógica de classe, ou, segundo Lefèbvre (1999), à sócio-lógica ou ideológica atuando na produção e fragmentação do solo urbano. As transformações físicas são acompanhadas por essa ideo-logia, pela produção de representações sobre os espaços e os sujeitos. É nesse sentido que as vilas de malocas são associadas à marginalidade, à precariedade e à não inserção dentro dos códigos de uma sociedade normatizada. Simultaneamente, a maloca contaminava e era contaminada por atos desviantes, que passavam de geração a geração, dada a promiscuidade do meio. Fica evidente que a dominação de classe manipula as representações, intensificando as alteridades, para manter o controle, como explicitado por Bourdieu:

A cultura dominante contribui para a integração real da classe dominante (assegurando uma comunicação imediata entre todos os seus membros e distinguindo-os das outras classes); para a integração fictícia da sociedade no seu conjunto, portanto, à desmobilização (falsa consciência) das classes dominadas; para a legitimação da ordem estabelecida por meio do estabelecimento das distinções (hierarquias) e para a legitimação dessas distinções. (BOURDIEU, 2007, p. 10).

$\mathrm{Na}$ manutenção do sistema de desigualdades, a maloca, enquanto expressão do habitar do segmento pobre, foi reduzida ao seu aspecto material e à não inserção na cidade que se almejava produzir. Contraditoriamente, o sistema urbano incorporou esse segmento, aproveitando a mão de obra barata, inserindo-os no mercado de trabalho informal. É nesse sentido que se deve desvincular a diferenciação social, materializada no acesso formal ao solo urbano, das possibilidades de consumo, que naturalizam, ocultam, dominam e perpetuam a estratificação social. O urbanismo, oculto na ideo-lógica, seria a solução para as patologias da cidade.

A percepção dos espaços é efêmera e mutável, pois, no movimento contínuo de escrita do urbano, as áreas de remoções foram refuncionalizadas e agregadas à cidade formal e desenvolvida. Constituiuse sob um conjunto de fatores materiais e simbólicos, que alteraram a representação do espaço, dado que o mesmo ocorre a partir das relações sociais, as quais foram violentamente alteradas. Para a população 
removida, fazia-se necessária a adequação mental e emocional à nova condição.

De um lado, há vidas e cotidianos, a ordem próxima; de outro, há o interesse do Estado e do capital, a ordem distante. A cidade passava por um momento de transformações radicais na forma e estrutura da rede urbana. Empreendeu-se a articulação da rede viária, que visava ampliar a circulação, os programas do DNOS (Departamento Nacional de Obras e Saneamento) para contenção de cheias e a produção de habitações. Para o novo modo de vida urbano, pautado em velocidade, circulação e assepsia, as sub-habitações eram entraves, ocupando áreas de interesse e cujas imagens eram contrárias ao novo modo de vida.

A modernidade e o progresso impuseram a segregação social que se concretizou nas políticas de remoção, legitimada pela própria modernização da cidade. Um dos momentos de remoção das malocas foi devido à ampliação da malha urbana, como pode ser observado nas notícias de jornal da época:

O Departamento Municipal de Habitação [declaração do então diretor da autarquia, Milton Pozzolo] iniciará hoje a remoção das malocas que estão impedindo o prolongamento da Avenida Princesa Isabel, próximo à Avenida Ipiranga. Cerca de 80 casebres que impedem o prolongamento d'aquela artéria que por coincidência é a rua da sede do DEMHAB, serão removidos para a Restinga, onde já se encontram os moradores que habitavam a Ilhota [sic]. (Zero Hora, 10 jul. 1967, p. 14).

O desenvolvimento urbano transformou lugares e vidas. Situação semelhante ocorreu com a construção da perimetral, da Free-way e da BR 290, como segue na reportagem:

Enquanto aguardava a hora da partida para São Paulo, o sapateiro João de Brito, a mulher e oito filhos continuavam morando na casa de número 584, na rua Avaí, desapropriada há alguns anos pela Prefeitura. Ontem os funcionários da companhia demolidora mandaram que os moradores se retirassem e, sem maiores explicações, começaram a destelhar o quarto do sapateiro João. É a perimetral que não pode esperar, arrasando as casas da Avaí, sem o menor interesse pela sorte dos moradores. (Zero Hora, 16 jul. 1969, p. 11). 
Em "Malocas da rua Avaí vão para a Restinga" (Zero Hora, 16 jan. 1970, p. 9), destaca-se a constituição da legitimidade da remoção frente à população, pois a associação entre os maloqueiros e os aspectos referentes à contravenção estavam diretamente relacionados.

Um grupo de maloqueiros, remanescentes da vila que existia nas imediações do início da futura avenida Perimetral, entre a rua Avaí e Travessa do Carmo, estão sendo transferidos para a Vila Restinga, próximo a Belém Novo. Com a medida, recentemente adotada pelo Departamento Municipal de Habitação (DEMHAB), fica solucionado um grave problema social existente na zona central. $\mathrm{O}$ grupo de malocas produzia mal-estar entre os habitantes do local, que se queixavam de roubos, atribuindo sua autoria aos maloqueiros [sic].

Outro momento que relaciona a produção de obras de infraestrutura, modernização e remoção são os projetos do DNOS. As obras do DNOS implicaram inúmeros reassentamentos para a Restinga, destacando-se as obras de canalização do arroio Dilúvio, a construção da Avenida Ipiranga, o dique de proteção da Vila Sarandi, as casas de bombas no bairro Navegantes, o aterro da Praia de Belas, o Dique Navegantes e o viaduto de Navegantes.

Constantemente as remoções eram relacionadas à limpeza, à assepsia e ao ordenamento. Elas vinham "libertar" a cidade da proximidade com a pobreza manifesta nas vilas de malocas.

Está sendo totalmente limpa a zona das proximidades da Ponte sobre o Guaíba, com o trabalho de remoção de malocas adquirindo um ritmo elogiável. A remoção, que é feita pelo DEMHAB, visa a rápida conclusão do trevo de acesso, à ponte e ainda a complementação das obras contra a seca do DNOS. De outra parte, o Departamento Municipal de Habitação, vem removendo malocas da faixa esquerda de quem vai do centro da Avenida Ipiranga. [sic] (Correio do Povo, 06 set. 1968, p. 7).

Quando a pobreza é explícita, a solução é escondê-la. A precariedade era uma realidade material e social, o que intensifica a perversidade da redução a uma questão estética, que levou a uma radical alteração da cartografia da cidade, que através do ideário de modernização promoveu, de um lado, a incorporação de setores considerados como deterioriorados e ausentes de urbanização e, de outro, criou áreas que, de forma contraditória 
ao suposto ideário, permaneceram um longo período com profundas ausências de infraestrutura urbana. Revela-se, portanto, a falácia do lema do programa — "Remover para promover" — , pois o eixo de desenvolvimento e geração de empregos predominava no centro administrativo, que devido à sua localização torna-se de fácil acesso aos municípios da região metropolitana e da zona norte, em contato com as vias de ligação com o norte do país (BR 101) e com o sul do estado (BR 290). A zona sul do município de Porto Alegre, local de acolhimento da população removida, era predominantemente rural, assim como Viamão, município vizinho.

No período de 1969 a 1974, foram removidas pela prefeitura de Porto Alegre 11.027 malocas, totalizando 48.194 pessoas, das quais algumas foram deslocadas para terrenos próprios e outras para áreas de recebimento dessa população, sendo que $10 \%$ das remoções tiveram como destino a Restinga Velha. Foi uma política intensiva, removendo aproximadamente duas mil malocas e 8 mil pessoas por ano (Zero Hora, 24 jan. 1975).

\section{Restinga: as contradições do "Remover para promover"}

A Restinga teve início a partir da ausência, da precariedade e de dificuldades superiores às vivenciadas nas malocas, pois eram as mesmas, com o diferencial do novo lugar, reduzindo o "promover" ao mero discurso. Mas havia também pessoas, histórias de vida, de opressões. A área do bairro foi adquirida em 1966, sendo primeiramente denominada como Restinga ${ }^{3}$ e, com a criação da Primeira Unidade Vicinal da Restinga Nova, passou a ser reconhecida como Velha Restinga. Atualmente, o bairro Restinga é um dos maiores de Porto Alegre, e a Restinga Velha é onde tudo começou.

A criação do bairro significou a emergência de uma situação que articulava elementos da espacialidade da conjuntura das vilas de malocas e da periferia. Junto com o morador veio a materialidade do estigma: a

${ }^{3} \mathrm{O}$ bairro cresceu muito desde sua origem, envolvendo hoje outros mecanismos de acesso à moradia: loteamentos irregulares, reassentamentos, aquisição de moradias populares e ocupações. Neste momento, a análise está centrada na origem do bairro, que se deu pelo processo de remoção das vilas de malocas. 
maloca, em que tanto a condição da habitação quanto do sujeito, o maloqueiro, constituíam uma espécie de "herança" material e simbólica que se sobrepunha à nova condição.

O espaço Restinga foi artificialmente criado a partir da ordem tecnocrática de uma corrente de pensamento que se colocava como racional e modernizante, reprojetando a conjuntura social, cuja manifestação teve materialidade na segregação socioespacial. Oculta na ideo-logia da higienização, havia a contradição do programa de urbanização, que incluía e excluía os sujeitos, defỉnindo quem partilharia dos benefícios da cidade moderna.

Em "Restinga, uma 'vila' ao abandono" (FAILLACE, Zero Hora, 18 maio. 1967, p. 12-13), tem-se explícita a contradição entre o discurso modernizante e a realidade posta no bairro:

Restinga, a nova Ilhota

Vocês conhecem a Restinga? Quarenta minutos de jipe, quarenta centavos novos de ônibus... A Restinga não é uma vila, nem uma granja, nem um loteamento. Não é coisa alguma. Um deserto. Areia fina e sêca, côr de cinza. Nem capim, nem árvores... capões de arbustos secos, também cinzentos, barbas de pau, plantas em agonia, uma sanga esverdeada de limo... Nem luz, nem água, nem comércio, nem hortas, nem indústria... nem trabalho. (...) A Restinga não tem coisa alguma. Isto é, tem gente. E malocas. Favela da Ilhota, que na solidão da Restinga tornou-se cinco vêzes favela. Acabada a vantagem do comércio camarada da zona, que fiava por semana, e até por quinzena... Acabada a vantagem da patroa compreensiva, que dava roupa velha e restos de comida para a faxineira... Acabada a vantagem dos lavados de roupa... Acabada a vantagem das reformas de vestidos... Acabada a novela ouvida no rádio do vizinho... Acabada a consulta à Santa Casa... Acabada a Feira Livre... Acabada a escola... Acabados os médicos, a farmácia, a Polícia, os bombeiros, os vizinhos... [sic] (FAILLACE, Zero Hora, 18 maio. 1967, p. 12-3).

O universo de relações sociais foi fortemente alterado, as estratégias de sobrevivência consolidadas foram perdidas e novos grupos, distintos, tiveram que se reordenar em um espaço marcado pelas ausências e pela distância. 
A água é fornecida de oito em oito dias por carros-tanques, que enchem as pipas públicas e as três ou quatro caixas d'água que existem... Água exposta a todas as contaminações. E quando o carro atrasa mais de quinze dias, êles bebem água da sanga... Em desespero de causa, os moradores tentaram perfurar poços por conta própria... só encontraram barro... A escola fica a mais de três quilômetros de distância e os pequenos que não podem caminhar tanto, perderam o ano... Os grandes perderam os empregos... [sic] (FAILLACE, Zero Hora, 18 maio. 1967 , p. 12-13)

Ora, o mal-estar gerado pela explicitação da pobreza nas malocas e pessoas se tornava invisível pela distância, e o objetivo de constituir uma cidade moderna e urbanizada tornava-se explicitamente seletivo ao relegar a população das remoções a condições mais insalubres do que as vivenciadas anteriormente às remoções.

Não são nem uma, nem duas as mulheres e as crianças que somaram seus esforços para reerguer, canhestramente, as velhas malocas, com as mesmas tábuas podres, os mesmos caixotes quebrados, os mesmos pregos tortos e enferrujados, usados inúmeras vezes... As casas são bem ventiladas, é preciso dizer-se... Algumas só têm três paredes, abertas como cenários teatrais, expondo escandalosamente a miséria de seu interior. Nas paredes levantadas, a média é de dois a três centímetros de folga entre uma tábua e outra... A chuva é pródiga. E, depois de uma tempestade, não há mais colchão nem roupa seca, nem corpo seco, de velha, velho, moça, moço, criança ou bebê. E não há mais tábuas, nem telhas, nem pregos para consertar os buracos. (FAILLACE, Zero Hora, 18 maio. 1967, p. 12-13).

As representações sociais sobre o bairro Restinga originaram-se na articulação das representações já constituídas acerca das malocas com a constituição da periferia: lugar distante, carente de infraestrutura e preenchido por uma população marginalizada. "Na Vila Dique, quando se fala em Restinga todo mundo pensa um pouco, coça o tornozelo esquerdo com os dedos do pé direito e acaba dizendo que seria bom, se não fosse tão longe." (Zero Hora, 20 fev. 1970, p. 2). A distância social foi sobreposta pela distância física.

A mídia atua como instrumento de disseminação de formas de pensar, mesclando representações de várias origens, do lugar, as ideologias 
do urbanismo... Em 1968, noticiava-se o bairro a partir dos elementos de precariedade e marginalidade: "Morte e desespero é só o que sobra na Restinga" (Zero Hora, 25 jan. 1969, p. 13). As palavras exercem importante função no processo de ancoramento das representações sociais, agregando-lhes significados, construindo os lugares do medo. Nesse sentido, o uso de termos como vietcong atua na ligação do espaço à condição de guerra, violência e ausência de uma ordem legitimada.

\section{(...) São cinco mil pessoas divididas em dois setores. Um de casas novas, o outro de malocas. A parte de casas velhas é chamada "vietcong", os que lá moram esperam sempre a conclusão de casas do setor novo, onde têm que pagar NCr\$ 11,00 por mês durante 15 anos, até serem proprietários. Mas a grande maioria não tem trabalho, não pode pagar mensalidade da casa própria. Quando procuram emprego e declaram onde moram, são mandados embora, pois, "na Restinga só mora ladrão”. (Zero Hora, 07 dez. 1968, p. 13).}

Juntamente com a constituição da Nova Restinga há a produção das alteridades vinculadas ao não acesso da população das malocas às novas moradias, além das disposições financeiras dos moradores da Velha Restinga, que era identificada como "vietcong", alusão à distância social que se constituía internamente no bairro.

A população sofria devido à remoção, o distanciamento do mercado de trabalho e o estigma vinculado à sua condição social. O processo de remoção foi marcado por forte repressão, dado que o direito de habitar a cidade ocorre pela posse formal da terra, fator primordial do pertencimento diferencial à cidade. Os habitantes das vilas de malocas não tinham o direito formal ao solo urbano, constituíam-se em ocupações e, portanto, não participavam do mercado do solo urbano enquanto seus consumidores. A alteridade posta no reconhecimento da legitimidade de estar no espaço justificou o processo de remoção. A irregularidade foi associada a um desajuste social, constituindo a distância física e o isolamento as soluções para não contaminar a sociedade e ressocializar essa população.

Vila Restinga simbolizou, dentro da problemática habitacional de Porto Alegre, uma espécie de "campo de concentração", para onde eram levadas as famílias residentes em núcleos irregulares. Quando o Departamento Municipal de Habitação (DEMHAB) adquiriu a área, propôs-se transformála em local de triagem, isto é, um lugar onde os moradores 
receberiam orientação técnica para a elevação de seu "status social”. (Zero Hora, 29 set. 1970, p. 3).

A hierarquização social impôs-se espacialmente na política de remoções, em que, a partir da legitimidade de ocupação formal e ditames morais, remetia o viver da população das Vilas de Malocas à condição de desajuste social. Essa sistemática de construção foi reproduzida no decorrer da década de 1970 e era recorrente nos veículos midiáticos: "Combate aos loteamentos clandestinos" (Zero Hora, 23 mar. 1972, p. 3).

A periferia é então construída fisicamente a partir dos reassentamentos, pela ausência de infraestrutura, saneamento, serviços públicos; socialmente, pela proximidade forçada, dado o assentamento de famílias de diversas vilas, pelas estratégias de sobrevivência que perpassavam as relações de proximidade; e, mentalmente, a partir das inúmeras representações do espaço, vinculando-o ao confinamento de segmentos desajustados da sociedade.

A urbanização, enquanto modo de vida que envolve políticas públicas supostamente de melhoramentos para a sociedade, atinge apenas seletivamente a cidade. A localização do bairro, no extremo sul, em um contexto de faltas, de distância do mercado de trabalho, associada à morfologia, que, além da existência de morros, é próximo ao lago Guaíba - tornando menos densa a estrutura viária —, é elemento que corroborava para o confinamento e a segregação dessa população. Oculta na ideologia, tem-se a própria produção da existência do segmento mais empobrecido, cuja condição social é ainda mais encoberta na própria malha urbana.

O "promover" do lema demorou a chegar ao bairro. Em janeiro de 1967, o então diretor do DEMHAB, afirmou que a área que abrigaria as malocas estava integralmente urbanizada para receber os maloqueiros (Zero Hora de 16 jan. 1967). Aproximadamente um mês depois, em reportagem do mesmo jornal, no dia 14 de fevereiro de 1967, assume-se que a área ainda não possuía energia elétrica, nem água, mas que em trinta dias esses problemas seriam solucionados. Em 22 de agosto de 1968, DEMHAB afirma que a implantação de energia elétrica havia sido encaminhada e que seriam escavados poços artesianos. No início de 1969, a situação ainda era precária, não existia iluminação pública, a qual seria efetivada em setembro do mesmo ano. Apenas em 1969 começaram as obras de implantação da rede de abastecimento de água para a Velha Restinga e a Restinga Nova; contudo, apenas a segunda teria a ligação domiciliar, iniciando também a produção de alteridades internas. A reportagem de Zero Hora de 25 de fevereiro de 1967 alerta para a existência de apenas quatro ônibus responsáveis pelo percurso para a 
Restinga, mas que em dois dias esse número aumentaria. Ainda em 1968, o problema persistia, não havendo ainda ônibus após as 21 horas. O sistema de transporte foi, durante longo tempo, outra falácia e deficiência que contribuía para o confinamento dessa população (MORAES, 2008).

A Restinga Velha (Figura 4) foi o primeiro momento de constituição do bairro, marcada pela distância, por ausências e constituída por sujeitos marginalizados pela sociedade. As dificuldades fizeram parte da história das pessoas, do pai, da mãe, do homem, da mulher, que passaram a ocupar um espaço rural, a percorrer uma distância muito maior, dependentes de um sistema de transporte oneroso e precário.

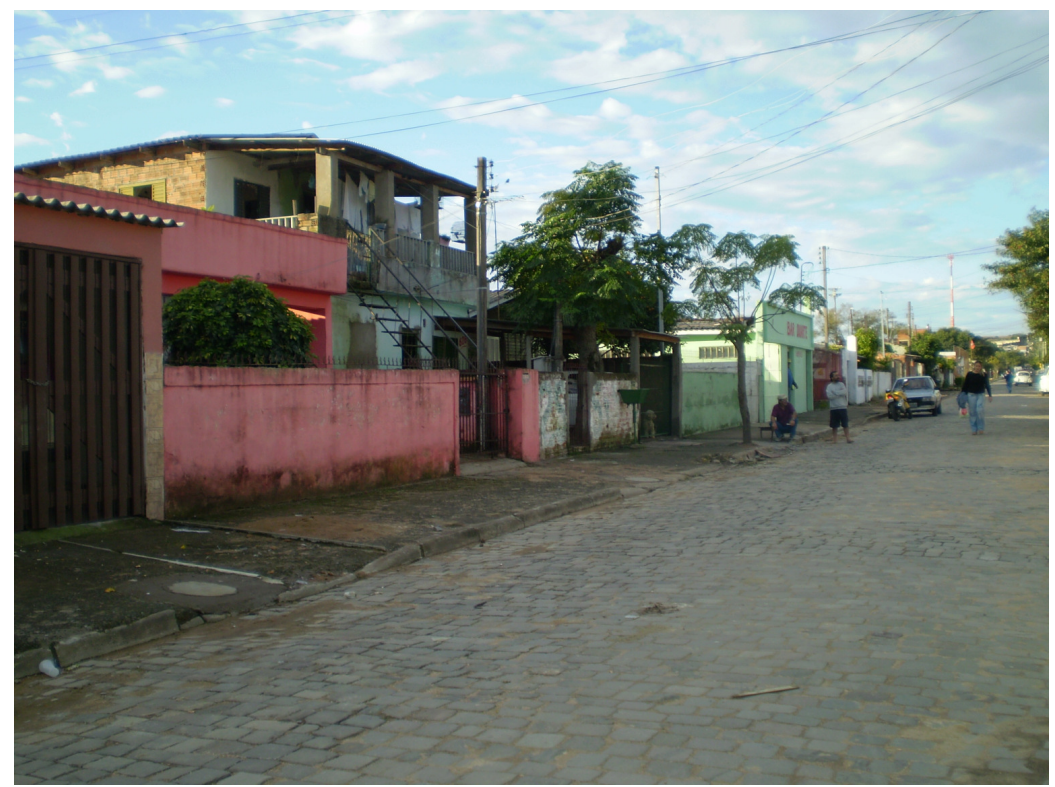

Figura 4. Restinga Velha Fonte: Nola Gamalho, julho de 2008.

\section{Considerações finais}

O bairro Restinga é um exemplo claro da articulação entre distintas lógicas: de um lado, ordem distante do Estado e, de outro, a ordem próxima. Na primeira, os sujeitos são "maloqueiros", indesejados; na segunda, são pessoas com histórias, lutas, trabalhadores... É importante repensar o bairro delineando as intencionalidades de sua produção. A Restinga se originou das vilas de malocas, de um pensamento que 
associava as vilas à promiscuidade, à patologia social, ao desajuste. Ao remover e constituir um novo espaço, essas representações foram somadas ao imaginário do novo bairro: tem-se a produção da periferia.

De vila de malocas passou a periferia, ainda lugar do pobre, das ausências, do feio, do insalubre, das promiscuidades... Essa transformação ocorreu sobre os estigmas já existentes, adquirindo nuances, roupagens diferentes, mas sem alterar significativamente o conteúdo de tais significações. As representações acerca do maloqueiro foram reprojetadas na periferia, do "vileiro".

Hoje, o imaginário acerca do bairro está relacionado ao medo, à "marginalidade", à "bandidagem, ao pobre, ao feio. Ora, passaram-se quarenta anos de sua origem e seus moradores ainda são pensados a partir de estigmas. Fica evidente a necessidade de desconfiar desse senso comum e compreender a produção do espaço para além de seus estigmas.

REMOVER PARA PROMOVER: ESPAÇO CONCEBIDO E REPRESENTAÇÕES DO ESPAÇO NO BAIRRO RESTINGA - PORTO ALEGRE/RS

Resumo: O presente trabalho tem como objetivo ampliar o entendimento da produção espacial, social e socioespacial do bairro Restinga, em Porto Alegre, RS. O ponto de partida é a concepção segundo a qual a produção do espaço é atravessada por materialidades, ideias, intenções e vidas, reconhecendo a intrínseca relação entre espaço e representação. Dessa forma, o trabalho reconstitui a produção do bairro a partir das remoções das vilas de malocas, identificando as representações do espaço (LEFEBVRE, 2000), seus mecanismos de produção e intencionalidades. O bairro Restinga surgiu a partir de estigmas que se perpetuam com novas roupagens nos dias de hoje. Dessa forma, é necessário reconstituir essa produção, recontando sua história.

Palavras-chave: espaço, representações, Restinga, Malocas

REMOVE TO PROMOTE: SPACE DESIGNED AND REPRESENTATIONS OF SPACE ON RESTINGA DISTRICT - PORTO ALEGRE / RS

Abstract: This paper aims to broaden the understanding of the production of Restinga Neighborhood, in Porto Alegre, RS. The production of space is 
understood as an intersection of materialities, ideas, intentions and lives, from which it is possible to recognize the intrinsic relationship between space and representation. Thus, it is possible to reconstruct the production of the neighborhood from the village of slums ("vila de malocas"), identifying the representation of space (LEFEBVRE, 2000), its devices of production and intentionalities. Restinga Neighborhood has arisen from stigmas, which persist with new colors nowadays. Hence, it is necessary to rebuild this production, retelling its history.

Keywords: space, representations, Restinga, slums

\section{BIBLIOGRAFIA}

BONDUKI, Raquel; BONDUKI, Nabil. (1982). Periferia da grande São Paulo. Reprodução do espaço como expediente de reprodução da força de trabalho. In: MẢRICATO, Ermínia (Org.). A produção capitalista da casa (e da cidade) no Brasil industrial. 2. ed. Alfa-Omega. p. 154-177. São Paulo.

BOURDIEU, Pierre. (2007) O poder simbólico. 6 ed. Bertrand Brasil. Rio de Janeiro.

CARDOSO, Cristiane. (2006). Do espaço concebido ao espaço vivido: um estudo de caso sobre as representações espaciais e identidades na Favela da Maré, RJ. 2006, 208 f. Tese (doutorado em geografia). Universidade Federal Fluminense, Centro de Estudos Gerais, Departamento de Geografia. Disponível em: <http://www.qprocura.com.br/dp/56789/Doespaco-concebido-ao-espaco-vivido:-um-estudo-de-caso-sobre-asrepresentacoes-espaciais-e-identidades-na-favela-da-Mare--RJ.html > Acesso em: 15 out. 2008. Niterói.

CARLOS, Ana Fani Alessandrini. (2001) Espaço-tempo na metrópole: a fragmentação da vida cotidiana. Contexto. São Paulo

. (2007) O espaço urbano: novos escritos sobre a cidade. Labur. São Paulo.

CÉLIO vai confinar malocas (1996). Zero Hora, ano 3, n.771, 17 de nov. p. 2. Porto Alegre.

COMBATE aos loteamentos clandestinos (1972). Zero Hora, ano 8, n. 2413, 23 mar. 1972, p. 3. Porto Alegre.

DEMHAB. (1969). Zero Hora, Zero Hora, ano 5, n. 1462, 27 fev., p. 2. Porto Alegre. 
FAILLACE, Tânia Jamardo. (1967) Zero Hora, , ano 4, n. 920, p12-13. Porto Alegre.

LEFEBVRE, Henri. (1999) A revolução urbana. Ed. UFMG. Belo Horizonte.

. (2000) La producion de l'espace. 4. ed. Paris: Anthropos.

. (2006) O direito à cidade. 4. ed. Centauro. São Paul

LEMOS, Eridson.(1968) Restinga, miséria é nome de vila pobre e difamada. Zero Hora, ano 5, n. 1395, 07 dez. p. 13. Porto Alegre.

MAGALHÃES, Daltro B. Dique, (1970) União e areia, tudo é uma vila só depois do trevo. Zero Hora, ano 6, n. 1769, p. 4. Porto Alegre.

MALOCAS da rua Avaí vão para a Restinga (1970). Zero Hora, ano 6, n. 1737, p. 9. Porto Alegre.

MALOCAS: DEMHAB continua remoção (1967). Zero Hora, ano 4, n. 695, 10 jul. p. 14. Porto Alegre.

MEDEIROS, Laudelino T. (1951). Vilas de malocas: ensaio de sociologia urbana. Manuscrito. Porto Alegre.

MORAES, Aldovan de Oliveira.(2008) Áreas do DEMHAB e conexa. 6. ed. , 3 v. Manuscrito. Porto Alegre.

MORTE e desespero (1969). Zero Hora, ano 5, n. 1435,p. 13. Porto Alegre.

MOSCOVICI, Serge. (2003) Representações sociais: investigações em psicologia social.Vozes. Petrópolis, RJ.

NOVA Restinga surgiu na mentalidade de sua gente. (1970) Zero Hora, ano 7, n. 1965, p. 3. Porto Alegre.

OS DEMOLIDORES estão à solta. (1969) Zero Hora, ano 6, n. 1577, p. 11. Porto Alegre.

PORTO ALEGRE. Prefeitura Municipal. (1973) Departamento Municipal de Habitação. Malocas: diagnóstico evolutivo das sub-habitações no município de Porto Alegre. Demhab. Porto Alegre.

PESAVENTO, Sandra Jatahy. (2001) Era uma vez o beco: origens do mau lugar. In: BRESCIANI, Maria Stella (Org). Palavras da cidade. Ed. Universidade/UFRGS, p. 97-119. Porto Alegre.

REMOVIDAS as malocas de três vias públicas.(1967) Correio do Povo, ano 73, n. 35, p. 10. Porto Alegre.

SANTOS, Milton. (1987). O espaço do cidadão. Nobel. São Paulo. 
.(2002). A natureza do Espaço: técnica e tempo, razão e emoção. EdUSP. São Paulo.

SOJA, Edward W. (1993). Geografias pós-modernas: a reafirmação do espaço na teoria social. Jorge Zahar. Rio de Janeiro.

TRATAMENTO urbanístico para ilha da pintada. (1968) Correio do Povo, ano 73, n. 283, p. 7. Porto Alegre.

Zero Hora (1970) ano 6, n. 1769, p.4. Porto Alegre.

48 mil maloqueiros removidos. (1975) Zero hora, ano 11, n. 3409, 24 jan. 1975, p. 11. Porto Alegre. 